\title{
AGRA ROMERO, MARIA XOSÉ (2016). ¿Olvidar a Clitemnestra? Sobre justicia e igualdad. Santiago de Compostela: Editorial Universidad de Santiago de Compostela, 222p.
}

\section{Tomeu Sales Gelabert}

La profesora Agra ha publicado este lúcido y brillante texto a medio camino entre la Teoría feminista y la Filosofía política, dos de sus grandes pasiones. Siguiendo la estela de sus maestros Celia Amorós, Fernando Quesada y José Montoya, realiza un inusual esfuerzo que liga mucho con su manera de escuchar el mundo. Un mundo complejo, con inseguridades y violencia, con contradicciones y ambigüedades. Un mundo que no pretende teorizar, sino escuchar, para pensarlo críticamente. La obra no aspira a ser un tratado, sino más bien una brújula moral y política. Esfuerzo humilde, que de buen seguro tendrá continuidad futura, y que rompe con la compartimentación y especialización extrema que ha dominado a la academia. Abrir la teoría feminista a la filosofía política y ésta a la teoría feminista se ha convertido en un esfuerzo titánico, pero necesario para romper con viejas inercias, que limitan y ciegan la capacidad de leer críticamente la realidad a través de conceptos; función principal de la filosofía crítica. Estamos pues, ante una obra que intentan romper dinámicas enquistadas y que pretende construir puentes. Ésta es la mejor defensa que se puede hacer de la filosofía en general, y de la teoría feminista y la filosofía política en particular.

La obra se abre con un retrato, un poema y una pregunta. Un retrato de Clitemnestra con hacha de doble filo (labrys) ensangrentada después del asesinato de Agamenón. Sale del palacio, corre la cortina y con mirada altiva, desafiante y penetrante mira al mundo. Obra del pintor prerrafaelita John Collier. Mujer que se muestra fuerte, valiente, que ha vengado el vil asesinato de su hija y que se abre al mundo como reina. Esta escena 
visualiza gran parte de los temas que se desarrollarán a lo largo de la obra: justicia, venganza, igualdad de los sexos, poder, filiación, afiliación, familia, violencia, asesinato, etc. Mimbres necesarios para adentrarse en la gramática de la justicia. El poema, la justicia por su mano, de Rosalía de Castro. Poema sobre justicia y venganza, donde la poetisa evoca las humillaciones que sufre como mujer y pobre frente a los oligarcas impartidores de una peculiar forma de "justicia”, la cual sólo tiene el nombre, ya que naturaliza la desigualdad tanto de clase como de sexo. Justicia que, aunque puede presentarse con ribetes de legalidad, no deja de ser ilegítima, ya que parte del desigual valor moral de los seres humanos. Indica la distancia entre la justicia legal y la moral, la necesidad de una verdadera concepción del igual valor del ser humano y el círculo de violencia que mantiene en marcha la ausencia de justicia. Y la pregunta, ¿Olvidar a Clitemnestra? Que se transforma en la siguiente pregunta, ¿Por qué recordar a Clitemnestra? A los más jóvenes desconocedores del debate feminista sobre la figura de Clitemnestra choca esta pregunta directa como título. Una vez se lea el libro, se entenderá la necesidad de recordar a Clitemnestra en tiempos de injusticias, violencia, asesinatos y discursos y contra-discursos donde aparecen vindicaciones feministas. Sin intentar desvelar el porqué, corre a cargo del lector, si la justicia rompe el circulo de violencia y asesinato, el silenciamiento histórico de Clitemnestra es la propia expresión de "las derrotas de las mujeres" (Agra, 2016: 14). He aquí uno de los grandes límites de la filosofía política a lo largo de su historia: el olvido y ausencia interesada de las voces de los oprimidos, vulnerables, precarios, dependientes, etc., en especial de las mujeres.

A lo largo de esta pequeña gran obra, la profesora no sólo hace un recorrido temático sobre una serie de cuestiones en torno a la justicia y la igualdad, sino también muestra un método de trabajo filosófico: dirigir la atención hacia aquellos que han sido silenciados. Voces ausentes en la mayor parte de las obras canónicas de la historia de la filosofía política y que obliga a una doble estrategia hermenéutica: acudir a textos menores y buscar las ausencias interesadas en los grandes textos y teorías de la filosofía política. Lo que en algunas ocasiones se ha considerado uno de los más fértiles enfoques feministas: la búsqueda del subtexto de género. Interrogarse por quién escribe, a quién escribe y por qué. En este sentido sostiene que: "El punto de partida e hilo conductor será que el feminismo es un lugar privilegiado para comprender la complejidad y los dilemas de una ciudadanía democrática y de una sociedad más justa” (Agra, 2016: 37).

El libro se estructura en cuatro grandes capítulos. En el primero se reivindica la Orestíada de Esquilo como la trilogía fundamental que muestra la justicia como institución social y política que rompe con el circulo vicioso de la violencia, el asesinato y la muerte. El segundo capítulo se titula ¿Dos justicias enfrentadas? En él vuelve a discutir el documento central, la Orestíada, en busca de la derrota de las mujeres, simbólicamente expresada en la absolución de Orestes y la condena y olvido de Clitemnestra. En el capítulo tercero, que lleva por título De los círculos viciosos a los giros de la justicia, sigue la discusión desde la 
concepción distributiva de la justicia de Aristóteles hasta la actualidad, parándose en las críticas feministas a la misma. El cuarto y último capítulo lleva por título Del giro cultural a las espirales virtuosas donde aborda dos cuestiones importantes: el giro culturalista en el debate de la justicia y la tormentosa relación entre feminismo y multiculturalismo.

La constante reivindicación de la Orestíada de Esquilo como documento crucial muestra la contribución de la justicia a la pacificación social, así como la oportunidad de un nuevo nacimiento, en sentido arendtiano. Su lectura y discusión da la oportunidad de volver a pensar la política y la justicia como aquello que puede romper el circulo vicioso de la muerte, violencia y venganza, convirtiéndolo en un círculo creativo/virtuoso para una nueva oportunidad para la vida y la convivencia (Agra, 2016: 26). Política, democracia y justicia aparecen entrelazadas desde su nacimiento en el mundo griego, y tal vez puedan suponer la posibilidad de una ruptura con las formas de violencia y muerte pre-políticas actuales. Ahora bien, ¿Qué orden social instituye la política y la justicia? Aquí aparece el fino análisis de la profesora Agra y su recuerdo de Clitemnestra. Se abren múltiples interrogantes: ¿Es aceptable cualquier orden social mientras pacifique el conflicto social? ¿Puede ser justo un orden social si no parte de una concepción radical del igual valor de los seres humanos? ¿La justicia democrática puede fundarse sobre la naturalización de la desigualdad?

La Orestíada no sólo es un documento crucial por mostrar como un orden político y justo es el camino para romper con la violencia, la muerte y la destrucción, sino también porque funda la justicia a partir de un orden social desigual. Orestes y Clitemnestra no son valorados de forma igual. El primero es absuelto, mientras que la segunda es condenada. ¿Hasta qué punto una justicia fundada sobre la desigualdad de los sexos puede romper el círculo de la violencia, muerte y venganza? Se evidencia que esta justicia es una justicia parcial; una "justicia patriarcal". Una justicia fundada en el desigual valor de los seres humanos será incapaz de alcanzar sus objetivos: romper con los ciclos de violencia. La tesis que sostiene la profesora Agra es que justicia e igualdad han de ir de la mano, convirtiéndose la gramática de la justicia en un afilado instrumento que advierte de las desigualdades, opresiones, subordinaciones y silenciamientos. Filosofía política y teoría feminista se dan la mano. La vindicación de la figura de Clitemnestra no se hace como ejemplo de emulación, ni búsqueda de venganza, sino como el recuerdo de que la justicia sin igualdad, y en concreto la igualdad de los sexos, no conseguirá romper el ciclo de la violencia, muerte y destrucción (Agra, 2016: 32). Olvidar a Clitemnestra es naturalizar un orden social político patriarcal. No se pide venganza, odio, violencia y asesinato, sino orden justo, orden igualitario. Clitemnestra es el símbolo de la lucha y al mismo tiempo de las contradicciones y vindicaciones del sujeto feminista.

La profesora Agra analiza las principales líneas de interpretación sobre la Orestíada de la mano de una gran cantidad de autores tales como: D. Raphael, M. Nussbaum, P. VidalNaquet, A. Iriarte, N. Louraux, K.L. Komar, S. Beauvoir, J. P. Sartre, J.J. Bachofen, F. 
Engels, K. Millet i M. Jufresa entre otras. La polifonía que despliega muestra no sólo la atención que dicha obra ha generado y sigue generando, sino también un dominio profundo de la discusión. La atracción de la Orestíada radica en que se está analizando un momento crucial: momento de ruptura del viejo orden y la emergencia de otro nuevo. Momento fundacional que marcará los derroteros de la democrática ática hasta su desaparición. Recordar que la Orestíada se estrena en el 458 a.C., cuatro años después de la reforma constitucional democrático-radical de Efialtes. Estamos en un momento de reestructuración de los patrones normativos que permitirán el tránsito de un orden aristocrático, basado en la desigualdad y la jerarquía, a un orden democrático, basado en la igualdad y la horizontalidad. Un momento que determinará y legitimará quienes son los iguales; es decir, quienes son los ciudadanos.

La absolución de Orestes y la condena de Clitemnestra aparece ligada al tránsito de una justicia tradicional basada en la retribución (cada cual según obró), por tanto, una justicia vengativa, a la justicia democrática, fundadora de orden pacífico en que los conflictos se resuelven en los tribunales y a través del voto. La venganza, la sangre, la filiación, el recuerdo de la víctima (su hija Ifigenia) y la memoria dejan paso a un nuevo orden igualitario preocupado por evitar cualquier fuente de conflicto interno (stasis). Pero como muy bien expone la profesora Agra de la mano de Louraux e Iriarte, la condena de Clitemnestra supone la derrota de las mujeres y la creación de las zonas de penumbra que acompañarán a la democracia ática: la exclusión de las mujeres del ámbito de los iguales y de la ciudadanía, y la despolitización de la familia, los cuidados y las responsabilidades. Las mujeres y la familia representan los elementos de desorden e inestabilidad que hay que conjurar. Para llevar a cabo esta operación se ponen en marcha diferentes dispositivos, entre los que hay que destacar el famoso mito de la autoctonía. Al final, la derrota de Clitemnestra simboliza la derrota de todas las mujeres como ciudadanas y como madres. Una auténtica operación silenciosa que marcará el gran déficit de la democracia ateniense y consolidará el imaginario socio-político sobre el cual trabajarán sin cuestionárselo los posteriores filósofos clásicos. Por tanto, no olvidar a Clitemnestra significa no olvidar y polemizar las exclusiones y zonas de penumbra sobre las que se construye el orden democrático. Lección que Esquilo lanza y que es aplicable a la actualidad (Agra, 2016: 76).

En capítulo tercero, aparece la discusión sobre la justicia distributiva desde Aristóteles hasta la actualidad de la mano de A. Domènech, A. Smith, J. Rawls, I. M. Young, M. Nussbaum, y N. Fraser. Se expone como se pasa de una concepción distributiva de la justicia basada en el mérito a otra, propiamente moderna, centrada en las necesidades y la distribución de bienes (Agra, 2016: 87). Volvemos a toparnos con la relación entre justicia e igualdad. En este recorrido, J. Rawls se sitúa como el que aporta "una clara formulación de la justicia distributiva moderna al afirmar la importancia de la individualidad humana y la necesidad de que, en consecuencia, la sociedad proteja a los individuos" (Agra, 2016: 
108). Se hace un fino análisis crítico de su teoría de la justicia distributiva, señalando sus virtudes (incorporación del lenguaje de la moralidad, el presupuesto del igual valor humano y la concepción extensa y estructural de la justicia) y sus límites (la asunción del lenguaje de la teoría de juegos, la a-historicidad y abstracción de su planteamiento). Sin pretender hacer una exhaustiva historia de la justica, la profesora Agra proporciona un hermoso fresco sobre el cual se pueden ver los diferentes "giros de la justicia": se pasa de una concepción legal de la justicia a una distributiva, y de ésta a una social, para acabar con la necesidad de una concepción política de la misma. En este sentido, introduce y analiza de forma pormenorizada las críticas feministas a la concepción distributiva rawlsiana de la justicia por parte de Young, Nussbaum y Fraser. Recordar que el interés de la profesora Agra está en analizar la articulación de la justicia y la igualdad, y no en formular una teoría de la justicia. Por tanto, su preocupación no se centrará tanto en un determinado criterio distributivo, como en observar los conflictos socio-políticos y las demandas de justicia. Se da un desplazamiento de la visión de la justicia a la escucha de las diferentes injusticias (Agra, 2016: 124). La justicia se mostrará ahora no tanto como el esfuerzo distributivo de bienes y servicios, en clave socialdemócrata, sino en el esfuerzo de desestabilizar las relaciones asimétricas de poder naturalizadas, por parte de las demandas de los nuevos movimientos sociales (Agra, 2016: 125). La justicia se abre a las demandas de los nuevos movimientos sociales. Entramos así en otro giro de la justicia que lleva de la distribución al reconocimiento, y de las diferentes fronteras de la justicia. Aborda este debate y llega a la conclusión de la necesidad de articular una justicia democrática en el sentido de que: "los procesos democráticos son el medio mejor para cambiar las condiciones de injusticia y para promover la justicia" (Agra, 2016: 151). Este largo periplo conduce al reconocimiento de que no basta sólo con la moralización de la justicia, sino que se necesita de su politización y democratización. Democracia y justicia se hacen extensivas.

El último capítulo entra en el debate sobre las demandas de las minorías de la mano del caso de Shah Bano, que expone los conflictos entre hindús y musulmanes, y de M. Nussbaum, S. Benhabib y A. Appadurai. La profesora Agra observa muy perspicazmente que: "atravesando estos debates, cultura significa género y el conflicto remite a la legislación, a la familia y a la esfera privada» (Agra, 2016: 157). Volvemos a darnos de bruces con las filiaciones y afiliaciones, la reproducción, las mujeres, el cuidado, la responsabilidad, etc., ámbitos y dimensiones donde se dan relaciones de poder jerárquicas y naturalizadas. Se pone de manifiesto como las mujeres son utilizadas como símbolo para hablar y expresar otros conflictos, convirtiéndose en un subterfugio o señuelo. En el debate sobre el multiculturalismo y las mujeres, éstas continúan siendo tratadas más como objeto que como sujeto. Estamos ante un nuevo silenciamiento y derrota de las mujeres.

De la mano de A. Philips, la profesora Agra apostará por no abordar las reivindicaciones culturales y las de género como totalidades cerradas y excluyentes. "Mantener esta 
separación refuerza las interpretaciones patriarcales de las tradiciones y valores culturales que, precisamente el feminismo ha cuestionado" (Agra, 2016: 179). La contraposición entre igualdad de los sexos y pluralismo cultural es una forma sesgada e interesada de plantear los debates en que casi con toda seguridad las mujeres tienen el peligro de perder. La solución a estos dilemas no es tanto normativa, como empírica y de acción política (Agra, 2016: 181). En este sentido aborda la discusión entre S. M. Okin y A. Shachar (Agra, 2016:191). Muestra tanto la necesidad como la complejidad del debate, que tiende a ser simplificado y conducido a través de un pensamiento dicotómico. Un debate que se enmarca dentro del esfuerzo por cuestionar las desigualdades, jerarquías y opresiones desde teorías igualitaristas que acuden al lenguaje de la justicia, aunque se producen tensiones (Agra, 2016: 203). Por tanto, en vez de cerrar el debate, apuesta por la discusión pública, racional y dialógica, empeñada no tanto en confeccionar una visión o teoría de la justicia como en escuchar las voces provenientes de las diferentes opresiones y desigualdades. Apuesta por la necesidad de una justicia contextual que, inspirada por principios normativos tales como el igual valor humano, sea capaz de escuchar las injusticias.

La propuesta de la profesora Agra se basa en el escuchar, modular el tono (evitando la soberbia desinteresada del teórico) y dar la talla (contextualizar el análisis y el discurso en un mundo multiescalar). Recordar a Clitemnestra es recordar a los silenciados. No se trata de exculpar a Clitemnestra, sino de que cualquier sociedad justa y democrática necesita de la escucha atenta e interesada frente a las injusticias, para evitar más derrotas (Agra, 2016: 209). Una justicia política, democrática, con mínimas bases normativas basadas en el igual valor de los seres humanos, atenta al conflicto, a las injusticias y desigualdades. En este sentido, no pretende articular una teoría cerrada y homogénea de la justicia, sino que ésta se convierte en un lenguaje moral, político y legal sobre el cual se inscriban las diferentes demandas que claman por ser escuchadas. Quedan abiertos nuevos interrogantes tales como: ¿Es posible la pacificación total del conflicto al que aspira la justicia democrática? ¿Se ha de hacer desaparecer el conflicto o canalizarlo? ¿Basta con la distribución o debemos de entrar en los conflictos socio-productivos? Estos y otros interrogantes nos mantendrán a la espera de nuevos desarrollos por parte de la profesora donde abra su particular concepción de la justicia y su ligazón con la igualdad. Animo a los lectores a que se acerquen a la obra y encontrarán desde la serenidad, el rigor y la profundidad, claves para hacer una lectura crítica de las dinámicas de un mundo que se asoma como desbocado por la violencia estructural y sistémica tanto cotidiana como estatal y global. Lectura de la mano de la gramática de la justicia, la igualdad, la política y la democracia. Un esfuerzo para repensar la constitución de un nuevo sujeto feminista que, aunque no reclame venganza exige ser escuchado y no olvidar a Clitemnestra. 